\title{
Persistent mitochondrial damage by nitric oxide and its derivatives: neuropathological implications
}

\author{
Juan P. Bolaños ${ }^{1 *}$ and Simon J. R. Heales ${ }^{2,3}$ \\ Department of Biochemistry and Molecular Biology, Institute of Neurosciences of Castilla- Leon, University of Salamanca, Salamanca, Spain \\ 2 Molecular and Genetics Unit, Institute of Child Health, University College London, London, UK \\ ${ }^{3}$ Department of Chemical Pathology, Great Ormond Street Hospital, London, UK
}

\section{Edited by:}

Ralf Dringen, University of Bremen,

Germany

\section{Reviewed by:}

Vitorio Calabrese, University of Catania, Italy

Vera Adam-Vizi, Semmelweis

University Budapest, Hungary

${ }^{*}$ Correspondence:

Juan P. Bolaños, Department of Biochemistry and Molecular Biology,

University of Salamanca, Edificio

Departamental Lab. 122, Campus

Miguel de Unamuno, 37007

Salamanca, Spain

e-mail: jbolanos@usal.es
Approximately 15 years ago we reported that cytochrome coxidase $(\mathrm{CcO})$ was persistently inhibited as a consequence of endogenous induction and activation of nitric oxide ( $\left.{ }^{*} \mathrm{NO}\right)$ synthase-2 (NOS2) in astrocytes. Furthermore, the reactive nitrogen species implicated was peroxynitrite. In contrast to the reversible inhibition by ${ }^{*} \mathrm{NO}$, which occurs rapidly, in competition with $\mathrm{O}_{2^{\prime}}$ and has signaling regulatory implications, the irreversible $\mathrm{CcO}$ damage by peroxynitrite is progressive in nature and follows and/or is accompanied by damage to other key mitochondrial bioenergetic targets. In purified $\mathrm{CcO}$ it has been reported that the irreversible inhibition occurs through a mechanism involving damage of the heme $\mathrm{a}_{3}-\mathrm{Cu}_{\mathrm{B}}$ binuclear center leading to an increase in the $K_{\mathrm{m}}$ for oxygen. Astrocyte survival, as a consequence of peroxynitrite exposure, is preserved due to their robust bioenergetic and antioxidant defense mechanisms. However, by releasing peroxynitrite to the neighboring neurons, whose antioxidant defense can, under certain conditions, be fragile, activated astrocytes trigger bioenergetic stress leading to neuronal cell death. Thus, such irreversible inhibition of $\mathrm{CcO}$ by peroxynitrite may be a plausible mechanism for the neuronal death associated with neurodegenerative diseases, in which the activation of astrocytes plays a crucial role.

Keywords: cytochrome c oxidase, nitric oxide, peroxynitrite, neurons, astrocytes, neurodegeneration

\section{CYTOCHROME COXIDASE IS PERSISTENTLY INHIBITED BY CONTINUOUS EXPOSURE TO NITRIC OXIDE/PEROXYNITRITE}

After the discovery of the potential biological roles of nitric oxide ('NO) (Ignarro et al., 1987; Palmer et al., 1987), its implication as a key player during glutamatergic neurotransmission was shortly reported (Garthwaite et al., 1988). By activating soluble guanylate cyclase (sGC), ${ }^{N} \mathrm{NO}$ thus participates in the signaling cascade leading to activation of cyclic GMP-dependent protein kinases (Garthwaite, 2008). Due to its multiple targets, it is now clear that ${ }^{*} \mathrm{NO}$ has a critical role for tissue survival, including the brain (Almeida et al., 1999; Pacher et al., 2007; Calabrese et al., 2009). In 1994, four independent laboratories reported that ${ }^{\circ} \mathrm{NO}$, either exogenously added to several preparations containing mitochondria, or endogenously produced in intact cells, via the inducible form of 'NO synthase (NOS2), inhibited cytochrome $c$ oxidase $(\mathrm{CcO})$, the terminal complex of the mitochondrial respiratory chain (Bolaños et al., 1994; Brown and Cooper, 1994; Cleeter et al., 1994; Schweizer and Richter, 1994). However, in the three laboratories that used exogenous 'NO, the effect on $\mathrm{CcO}$ was found to be reversible (Brown and Cooper, 1994; Cleeter et al., 1994; Schweizer and Richter, 1994) and in competition with $\mathrm{O}_{2}$ (Brown and Cooper, 1994; Schweizer and Richter, 1994), whereas in the other study (Bolaños et al., 1994), which relied upon endogenous/sustained ' $\mathrm{NO}$ formation, inhibition of $\mathrm{CcO}$ activity was found to be progressive and persistent.

The implications of the reversible interaction of $\mathrm{CcO}$ with $\mathrm{NO}$ for cell signaling and physiology are of paramount importance (Levonen et al., 2001; Brookes et al., 2002; Cooper, 2002; Brown, 2007; Taylor and Moncada, 2009), although there still remain some issues that may require further validation (Garthwaite, 2008).
For instance, the concomitant bioenergetic stress following $\mathrm{CcO}$ inhibition by NO increases the AMP:ATP ratio that, by stimulating the AMP-activated protein kinase (AMPK), switches on glycolysis (Almeida et al., 2004). In addition, a reduction in cytochrome $c$ is followed by the inhibition of $\mathrm{CcO}$ by ${ }^{~} \mathrm{NO}$, and this enhances mitochondrial superoxide formation $\left(\mathrm{O}_{2}^{-}\right)$that activates signaling pathways involved in cytoprotection (Moncada and Erusalimsky, 2002; Moncada and Bolanos, 2006) and hypoxic effects (PalaciosCallender et al., 2007). Moreover, during 'NO-mediated interaction with $\mathrm{CcO}, \mathrm{O}_{2}^{-}$formation is observed even before an inhibition of respiration is observed (Palacios-Callender et al., 2004; Jacobson et al., 2005). Interestingly, reduced cytochrome $c$ can also react with $\mathrm{NO}$ to produce the nitroxyl anion $\left(\mathrm{NO}^{-}\right)$species (Sharpe and Cooper, 1998b; Parihar et al., 2008). Furthermore, either $\mathrm{O}_{2}^{--}$ and $\mathrm{NO}$ (Blough and Zafiriou, 1985), or $\mathrm{O}_{2}$ and $\mathrm{NO}^{-}$(Sharpe and Cooper, 1998b; Parihar et al., 2008), can spontaneously react to form the very unstable pro-oxidant peroxynitrite anion $\left(\mathrm{ONOO}^{-}\right)$. Thus, through the interaction of $\mathrm{NO}$ with $\mathrm{CcO}$, mitochondria become both the target of $\mathrm{NO}$ and the site of peroxynitrite formation. However, as unraveled by other laboratories, extra-mitochondrial formation of peroxyntirite, for instance through the reaction of 'NO with plasma membrane NADPH-derived $\mathrm{O}_{2}^{-}$(Bal-Price et al., 2002; Mander and Brown, 2005), can also occur.

\section{OTHER MITOCHONDRIAL TARGETS OF PEROXYNITRITE}

Regardless of the specific source of formation, peroxyntirite can easily diffuse through membranes due to its high lipid solubility (Lim et al., 2008), and hence it can reach targets distant from its site of production. In fact, peroxynitrite is implied in damages 
to several cellular components, including essential mitochondrial proteins such as aconitase (Castro et al., 1994; Gardner et al., 1997; Tortora et al., 2007), NADH dehydrogenase (Radi et al., 1994; Borutaite et al., 2000), succinate dehydrogenase (Radi et al., 1994), $\alpha$-ketoglutarate dehydrogenase (Park et al., 1999), amongst other mitochondrial targets (Radi et al., 2002), DNA (Inoue and Kawanishi, 1995; Uppu et al., 1996; Cantoni and Guidarelli, 2008) and lipids (Patel and Darley-Usmar, 1996). It is now also very well accepted that peroxynitrite can be formed in vivo (Beal, 2002), and is likely to modify or damage a still undetermined number of proteins (Liaudet et al., 2009). The exact mechanisms whereby peroxynitrite interacts with proteins are not known. The most common reactions involve nitration of tyrosine on its position 3 (Radi, 2004) and oxidation of sulfhydryls (Radi et al., 1991), both of which can modify critical structures of proteins leading to change in activity (most likely inactivation). In fact, immunodetection of 3 -nitrotyrosines in proteins of biological samples is now considered a good reflection of peroxynitrite formation (Greenacre and Ischiropoulos, 2001; Bolanos et al., 2004). Furthermore, critical proteins have been shown to be both nitrosylated (i.e., nitrated on tyrosine residues) and oxidized (i.e., sulfhydryl oxidation), such as mitochondrial NADH dehydrogenase (Landino, 2008), giving rise to a complex way of modulation of enzyme activity that still requires further elucidation.

\section{ON THE MECHANISM OF PEROXYNITRITE INTERACTION WITH CYTOCHROME COXIDASE}

The molecular mechanism responsible for the irreversible inhibition of $\mathrm{CcO}$ by peroxyntirite was first investigated by Sharpe and Cooper (Sharpe and Cooper, 1998a). They revealed a complex interaction between peroxyntirite and purified $\mathrm{CcO}$ causing an increase in the $K_{\mathrm{m}}$ for $\mathrm{O}_{2}$ and a decrease in the $V_{\max }$ of the enzyme, as well as spectra changes compatible with oxidation of the $\mathrm{a}_{3}$ center, partial reduction of cytochrome $a$, and irreversible damage to the $\mathrm{Cu}_{\mathrm{A}}$ site (Sharpe and Cooper, 1998a; Pearce et al., 1999). The decrease in $V_{\max }$ observed by Sharpe and Cooper (1998a) is compatible with the $25 \%$ inhibition of the specific activity of COX in astrocytes activated to endogenously produce peroxynitrite (Bolaños et al., 1994). Regardless the specific mechanism leading to CcO irreversible damage by peroxynitrite, it is now clear that this interaction may have a still non-conceived pathophysiological implications (Cooper et al., 2003).

\section{BRAIN IMPLICATIONS OF THE PEROXYNITRITE-CYTOCHROME COXIDASE INTERACTION}

Due to its high-energy requirements to support ionic balance and neurotranmission (Hertz et al., 2007; Nehlig and Coles, 2007; Pellerin et al., 2007; Cai and Sheng, 2009), the central nervous system is one of the most vulnerable targets to mitochondrial impairment. However, the brain is a complex tissue formed by the organization of four well-differentiated neural cell types, including neurons, astrocytes, microglia and oligodendrocytes (Hertz et al., 2007). Such cell types do not act in isolation, as a degree of active collaboration exists between the differing cells, e.g. astrocytes are involved in glutamate homeostasis and the trafficking of antioxidants to neuronal cells (Fellin, 2009; Perea et al., 2009). Furthermore, astrocytes and neurons establish a mutual paracrine-like communication system through the release of soluble and cell permeable factors, involving cytokines (Peuchen et al., 1997), reactive oxygen and nitrogen species (RONS) (Whitney et al., 2009) or substrate precursors (Pellerin et al., 2007) (Figure 1).

With regards to astrocytes, the presence of cytokines (interferon- $\gamma$, interleukine- $1 ß$ or tumor necrosis factor- $\alpha$ ), immunogenic neuronal proteins (S100ß) or other exogenous components such as viruses or bacterial endotoxins, such as lipopolysaccharide (LPS) trigger the transcription of a number of genes leading to a situation generally known as activation (Peuchen et al., 1997). Activated astrocytes are characterized by certain small morphological changes (Hertz et al., 2007) and by the release of RONS, including ${ }^{-N O}$ and $\mathrm{ONOO}^{-}$(Peuchen et al., 1997). There are now a number of human diseases associated with this type of neuroinflammatory picture. These include multiple sclerosis (Nair et al., 2008), Alzheimer's and Parkinson's diseases (McGeer and McGeer, 2008; Rodriguez et al., 2009).

\section{DIFFERENT VULNERABILITY BETWEEN NEURONS AND ASTROCYTES AGAINST NITROSATIVE DAMAGE}

Our own previous data reported that activated atrocytes, which express NOS2 (Murphy et al., 1993), continuously release a considerable amount of ${ }^{\circ} \mathrm{NO}$ (Brown et al., 1995), which is responsible for their inhibition of $\mathrm{CcO}$ activity (Bolaños et al., 1994). Moreover, the persistent inhibition of $\mathrm{CcO}$ ( $\sim 25 \%$ inhibition of complex activity) had functional consequences to mitochondrial respiration, since complete removal of ${ }^{\circ} \mathrm{NO}$ from the activated astrocytes significantly reduced (by $\sim 18 \%$ ) their rate of oxygen consumption (Brown et al., 1995). However, these cells were shown to be highly resistant to any survival problem triggered by such inhibition, and the identification of a NOS2-mediated increase in the rate of glucose conversion to lactate suggested that the ensuing mitochondrial bionergetic crisis was compensated by the up-regulation of glycolysis (Bolaños et al., 1994). In fact, further investigation into this issue has revealed a specific mechanism linking mitochondrial inhibition to glycolysis up-regulation by NO involving the switching on of the 5'AMPactivated protein kinase-6-phosphofructo-2-kinase/fructose2,6-bisphosphatase (isoform 3) pathway in astrocytes, but not in neurons (Almeida et al., 2004). Thus, astrocytes are activated cells that can release large amounts of RONS without compromising their own survival. However, due to the lipid solubility nature of RONS, the neighboring neurons may become vulnerable targets.

In order to study the metabolic consequences of activated astrocytes to neurons, we used a neuronal-astrocyte co-culture system to more closely resemble the interaction between these two cells in vivo. Thus, astrocytes grown on the surface of a co-culture microwell membrane device were first challenged to induce NOS2 by incubation with interferon- $\gamma$ and LPS. When activated astrocytes produced large amounts of $\mathrm{NO}$, they were posed on the top of a neuronal culture monolayer (Bolaños et al., 1996) and further incubated for several time points, either in the presence or in the absence of the NOS inhibitor N-monomethyl-L-arginine (NMMA). We found that $24 \mathrm{~h}$ after the co-incubation period, neurons showed a NMMA-sensitive inhibition of $\mathrm{CcO}$ activity (Bolaños et al., 1996) that, in contrast to the damage to other components 


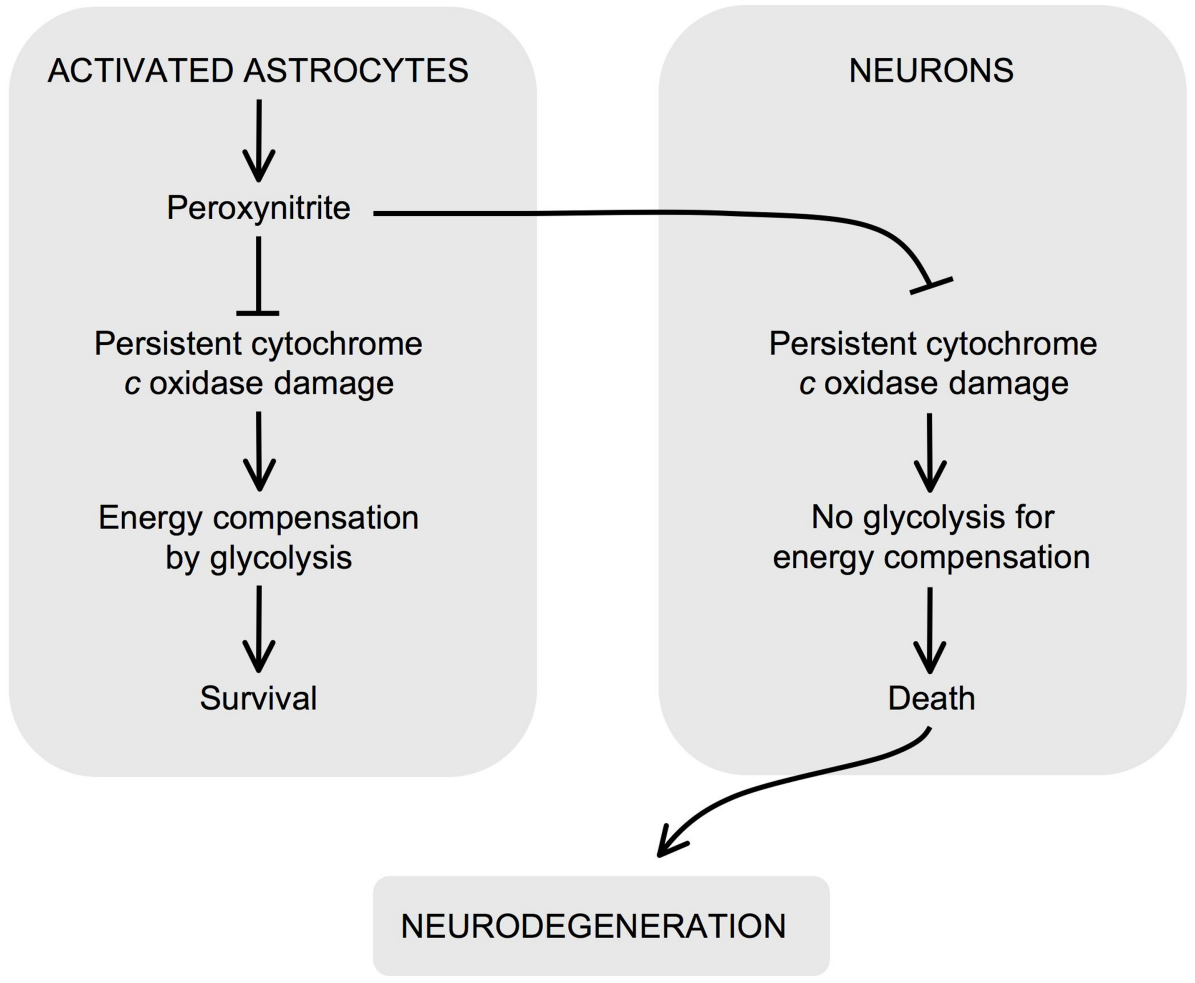

FIGURE 1 | Role for irreversible inhibition of cytochrome $\boldsymbol{c}$ oxidase in neurodegeneration. Peroxynitrite can be formed in astrocytes upon activation. In astrocytes, peroxyntrite irreversibly damages cytochrome $c$ oxidase, which causes mitochondrial dysfunction. However, these cells compensate the energy deficiency by activating glycolysis and survive.

Peroxynitrite is a highly diffusible molecule, and hence it reaches neighboring neurons, where it irreversibly damages cytochrome coxidase. In contrast to astrocytes, neurons cannot up-regulate the energy-compensating glycolysis and hence they die by bioenergetic crisis. Thus, the irreversible inhibition of cytochrome $c$ oxidase by peroxynitrite has a critical negative effect on neuronal survival and may contribute to the propagation of neurodegeneration. of the mitochondrial respiratory chain, was time-dependent and permanent (Stewart et al., 2000), causing a bioernergetic deficiency leading to cell death (Bolaños et al., 1996). Thus, incubation of neurons to peroxynitrite-producing astrocytes for $24 \mathrm{~h}$ is followed by subsequent full recovery of COX activity; however, such recovery does not take place if the period of incubation was $48 \mathrm{~h}$ (Stewart et al., 2000). These results suggest that COX would remain inhibited as long as peroxynitrite is present, hence respiration at COX recovers depending on the enzyme turnover rate. It should also be mentioned that other components of the mitochondrial respiratory chain are also damaged, though at much lower extent, by endogenous peroxynitrite in astrocytes, including succinate-cytochrome c oxidoreductase (Bolaños et al., 1994; Hargreaves et al., 2007), and NADH-ubiquinone oxidoreductase (Bolaños et al., 1994). Moreover, these results clearly demonstrated that activated astrocytes can damage neighboring neurons through a mechanism in which ${ }^{\mathrm{NO}}$ and/or ${ }^{\circ} \mathrm{NO}$-derivatives are involved. However, it was intriguing that neurons were relatively resistant against activated astrocytes when compared with the high vulnerability of neurons if incubated, alone, with several pro-oxidant compounds (Bolaños et al., 1995, 1996). The role for antioxidant glutathione in neuroprotection against the neurotoxic effects of nitric oxide was thus first proposed (Bolaños et al., 1995, 1996).

\section{PROTECTIVE ROLE FOR GLUTATHIONE AGAINST PEROXYNITRITE-MEDIATED NEURONAL DAMAGE}

Incubation of neurons with exogenous peroxynitrite triggered a dose-dependent persistent inhibition of $\mathrm{CcO}$ that is not observed in astrocytes at identical concentrations (Bolaños et al., 1995). Such an effect was correlated with a deficiency in the intracellular concentrations of glutathione in neurons, being astrocytes highly resistant to such effect (Bolaños et al., 1995). In contrast, when neurons were incubated in the presence of activated astrocytes, the limited effect on ATP concentrations and neuronal survival suggested the development of a protective mechanism not existing in the neurons when cultured alone (Bolaños et al., 1996). By investigating this, we found that neurons increased their intracellular concentration of glutathione by the presence of either resting or activated astrocytes (Bolaños et al., 1996), indicating the transfer of glutathione, or its direct precursor, from astrocytes to neurons. The mechanism and implications for the transfer of this astrocyte-neuronal glutathione precursors has been confirmed and studied in depth (Dringen et al., 1999). In fact, co-incubation of neurons with glutathione-depleted astrocytes resulted in a much higher vulnerability of neurons against astrocyte-derived ' $\mathrm{NO}$ and/or $\mathrm{ONOO}^{-}$(Gegg et al., 2005), suggesting that the astrocyte antioxidant capacity must be preserved in order to efficiently protect neurons against damage. However, glutathione 
deficiency can also be damaging to the astrocytes themselves, since glutathione depletion dramatically increase the susceptibility of astrocytes to peroxynitrite at doses that are not damaging in normal astrocytes (Barker et al., 1996). Thus, the role for intercellular glutathione exchange between neurons and astrocytes are currently considered to be a major target for neuroprotection (Vargas et al., 2008; Miller et al., 2009; Sandhu et al., 2009).

\section{CONCLUDING REMARKS}

In conclusion, whilst the reversible modulation of $\mathrm{CcO}$ by ${ }^{\circ} \mathrm{NO}$ is of paramount importance for the physiological regulation of cell functions, the persistent interaction of its endogenous derivative peroxynitrite with this mitochondrial complex may have profound and permanent consequences for cell survival. This is of particular importance in the central nervous system, since neurons are particularly vulnerable cells against mitochondrial impairment (Bolaños et al., 1995), possibly due to their unability to up-regulate glycolysis and hence to compensate for any bioenergetic crisis

\section{REFERENCES}

Almeida, A., Bolaños, J. P., and Medina, J. M. (1999). Nitric oxide mediates glutamate-induced mitochondrial depolarization in rat cortical neurons. Brain Res. 816, 580-586.

Almeida, A., Moncada, S., and Bolaños, J. P. (2004). Nitric oxide switches on glycolysis through the AMP protein kinase and 6-phosphofructo2-kinase pathway. Nat. Cell Biol. 6, 45-51.

Atamna, H., and Frey, W. H. II (2007). Mechanisms of mitochondrial dysfunction and energy deficiency in Alzheimer's disease. Mitochondrion 7, 297-310.

Bal-Price, A., Matthias, A., and Brown, G.C. (2002). Stimulation of the NADPH oxidase in activated rat microglia removes nitric oxide but induces peroxynitrite production. J. Neurochem. 80, 73-80.

Barker, J. E., Bolaños, J. P., Land, J. M., Clark, J. B., and Heales, S. J. R. (1996). Glutathione protects astrocytes from peroxynitrite-mediated mitochondrial damage: implications for neuronal/ astrocytic trafficking and neurodegeneration. Dev. Neurosci. 18, 391-396.

Beal, M. F. (2002). Oxidatively modified proteins in aging and disease. Free Radic. Biol. Med. 32, 797-803.

Blough, N. V., and Zafiriou, O. C. (1985). Reactions of superoxide with nitric oxide to form peroxonitrite in alkaline aqueous solution. Inorg. Chem. 24, 3502-3504.

Bolanos, J. P., Garcia-Nogales, P., and Almeida, A. (2004). Provoking neuroprotection by peroxynitrite. Curr. Pharm. Des. 10, 867-877.

Bolaños, J. P., Heales, S. J. R., Land, J. M., and Clark, J. B. (1995). Effect of peroxynitrite on the mitochondrial respiratory chain: differential susceptibility of neurones and astrocytes in primary cultures. J. Neurochem. 64, 1965-1972.

Bolaños, J. P., Heales, S. J. R., Peuchen, S., Barker, J. E., Land, J. M., and Clark, J. B. (1996). Nitric oxide-mediated mitochondrial damage: a potential neuroprotective role for glutathione. Free Rad. Biol. Med. 21, 995-1001.

Bolaños, J. P., Peuchen, S., Heales, S. J. R., Land, J. M., and Clark, J. B. (1994). Nitric oxide-mediated inhibition of the mitochondrial respiratory chain in cultured astrocytes. J. Neurochem. 63, 910-916.

Borutaite, V., Budriunaite,A., and Brown, G. C. (2000). Reversal of nitric oxide-, peroxynitrite- and S-nitrosothiol-induced inhibition of mitochondrial respiration or complex I activity by light and thiols. Biochim. Biophys. Acta 1459, 405-412.

Brookes, P. S., Levonen, A. L., Shiva, S., Sarti, P., and Darley-Usmar, V. M. (2002). Mitochondria: regulators of signal transduction by reactive oxygen and nitrogen species. Free Radic. Biol. Med. 33, 755-764.

Brown, G. C. (2007). Nitric oxide and mitochondria. Front. Biosci. 12, 1024-1033. doi:10.4067/S071697602000000200018.

Brown, G. C., Bolaños, J. P., Heales, S. J. produced by activated astrocytes rapidly and reversibly inhibits cellular respiration. Neurosci. Lett. 193, 201-204.

Brown, G. C., and Cooper, C. E. (1994). Nanomolar concentrations of nitric oxide reversibly inhibit synaptosomal respiration by competing with oxygen at cytochrome oxidase. FEBS Lett. 356, 295-298.

Cai, Q., and Sheng, Z. H. (2009). Molecular motors and synaptic assembly. Neuroscientist 15, 78-89.

Calabrese, V., Cornelius, C., Rizzarelli, E., Owen, J. B., Dinkova-Kostova, R., and Clark, J. B. (1995). Nitric oxide

(Bolaños et al., 1995; Herrero-Mendez et al., 2009). In addition, the glutathione-dependent fragile nature of neurons compromise their defense against the release of RONS from activated glial cells, which trigger permanent damage to $\mathrm{CcO}$ and also to other critical mitochondrial components. Thus, the irreversible inhibition of $\mathrm{CcO}$ by peroxynitrite may be a critical contributing factor for the neuronal death accompanying neurodegenerative disorders, such as Alzheimer's and Parkinson's diseases (Ebadi and Sharma, 2003; Atamna and Frey, 2007; Fukui and Moraes, 2008), in which CcO (Parker et al., 1990) and glutathione deficiency (Perry et al., 1982), are hallmarks.

\section{ACKNOWLEDGMENTS}

Juan P. Bolaños is supported by the Ministerio de Ciencia e Innovación (SAF2007-61492 and Consolider-Ingenio CSD200700020, Spain) and by the Junta de Castilla y León (SA046A102; Grupo de Excelencia GR206 and Red de Terapia Celular y Medicina Regenerativa).

A. T., and Butterfield, D. A. (2009). Nitric oxide in cell survival: a janus molecule. Antioxid. Redox Signal. 11, 2717-2739.

Cantoni, O., and Guidarelli, A. (2008) Peroxynitrite damages U937 cell DNA via the intermediate formation of mitochondrial oxidants. IUBMB Life 60, 753-756.

Castro, L., Rodríguez, M., and Radi, R. (1994). Aconitase is readily inactivated by peroxynitrite, but not by its precursor, nitric oxide. J. Biol. Chem. 269, 29409-29415.

Cleeter, M. W. J., Cooper, J. M., DarleyUsmar, V. M., Moncada, S., and Schapira, A. H. (1994). Reversible inhibition of cytochrome $c$ oxidase, the terminal enzyme of the mitochondrial respiratory chain, by nitric oxide. Implications for neurodegenerative diseases. FEBS Lett. 345, 50-54.

Cooper, C. E. (2002). Nitric oxide and cytochrome oxidase: substrate, inhibitor or effector? Trends Biochem. Sci. 27, 489-492.

Cooper, C.E., Davies, N.A., Psychoulis, M., Canevari, L., Bates, T.E., Dobbie, M.S., Casley, C. S., and Sharpe, M.A. (2003). Nitric oxide and peroxynitrite cause irreversible increases in the $\mathrm{K}(\mathrm{m})$ for oxygen of mitochondrial cytochrome oxidase: in vitro and in vivo studies. Biochim. Biophys. Acta 1607, 27-34.

Dringen, R., Pfeiffer, B., and Hamprecht, B. (1999). Synthesis of the antioxidant glutathione in neurons: supply by astrocytes of CysGly as precursor for neuronal glutathione. J. Neurosci. 19, 562-569.

Ebadi, M., and Sharma, S. K. (2003) Peroxynitrite and mitochondrial dysfunction in the pathogenesis of Parkinson's disease. Antioxid. Redox Signal. 5, 319-335.
Fellin, T. (2009). Communication between neurons and astrocytes: relevance to the modulation of synaptic and network activity. J. Neurochem. 108, 533-544.

Fukui, H., and Moraes, C. T. (2008). The mitochondrial impairment, oxidative stress and neurodegeneration connection: reality or just an attractive hypothesis? Trends Neurosci. 31, 251-256.

Gardner, P. R., Costantino, G., Szabo, C., and Salzman, A. L. (1997). Nitric oxide sensitivity of the aconitases. $J$. Biol. Chem. 272, 25071-25076.

Garthwaite, J. (2008). Concepts of neural nitric oxide-mediated transmission. Eur. J. Neurosci. 27, 2783-2802.

Garthwaite, J., Charles, S. L., and ChessWilliams, R. (1988). Endotheliumderived relaxing factor release on activation of NMDA receptors suggests a role as intercellular messenger in the brain. Nature 336, 385-387.

Gegg, M. E., Clark, J. B., and Heales, S. J. (2005). Co-culture of neurones with glutathione deficient astrocytes leads to increased neuronal susceptibility to nitric oxide and increased glutamatecysteine ligase activity. Brain Res. 1036, 1-6.

Greenacre, S. A., and Ischiropoulos, H. (2001). Tyrosine nitration: localisation, quantification, consequences for protein function and signal transduction. Free Radic. Res. 34, 541-581.

Hargreaves, I. P., Duncan, A. J., Wu, L., Agrawal, A., Land, J. M., and Heales, S. J. (2007). Inhibition of mitochondrial complex IV leads to secondary loss complex II-III activity: implications for the pathogenesis and treatment of mitochondrial encephalomyopathies. Mitochondrion 7, 284-287.

Herrero-Mendez, A., Almeida, A., Fernandez, E., Maestre, C., Moncada, S., and Bolanos, J. P. (2009). The bioenergetic and antioxidant status of 
neurons is controlled by continuous degradation of a key glycolytic enzyme by APC/C-Cdh1. Nat. Cell Biol. 11, 747-752.

Hertz, L., Peng, L., and Dienel, G. A. (2007). Energy metabolism in astrocytes: high rate of oxidative metabolism and spatiotemporal dependence on glycolysis/glycogenolysis. J. Cereb. Blood Flow Metab. 27, 219-249.

Ignarro, L. J., Buga, G. M., Wood, K. S., Byrns, R. E., and Chaudhuri, G. (1987). Endothelium-derived relaxing factor produced and released from artery and vein is nitric oxide. Proc. Natl. Acad. Sci. U.S.A. 84, 9265-9269.

Inoue, S., and Kawanishi, S. (1995). Oxidative DNA damage induced by simultaneous generation of nitric oxide and superoxide. FEBS Lett. 371, 86-88.

Jacobson, J., Duchen, M. R., Hothersall, J., Clark, J. B., and Heales, S. J. (2005). Induction of mitochondrial oxidative stress in astrocytes by nitric oxide precedes disruption of energy metabolism. J. Neurochem. 95, 388-395.

Landino, L. M. (2008). Protein thiol modification by peroxynitrite anion and nitric oxide donors. Meth. Enzymol. 440, 95-109.

Levonen, A. L., Patel, R. P., Brookes, P., Go, Y. M., Jo, H., Parthasarathy, S., Anderson, P. G., and Darley-Usmar, V. M. (2001). Mechanisms of cell signaling by nitric oxide and peroxynitrite: from mitochondria to MAP kinases. Antioxid. Redox Signal. 3, 215-229.

Liaudet, L., Vassalli, G., and Pacher, P. (2009). Role of peroxynitrite in the redox regulation of cell signal transduction pathways. Front. Biosci. 14, 4809-4814.

Lim, C. H., Dedon, P. C., and Deen, W. M. (2008). Kinetic analysis of intracellular concentrations of reactive nitrogen species. Chem. Res. Toxicol. 21, 2134-2147.

Mander, P., and Brown, G. C. (2005). Activation of microglial NADPH oxidase is synergistic with glial iNOS expression in inducing neuronal death: a dual-key mechanism of inflammatory neurodegeneration. $J$. Neuroinflammation 2, 2-20.

McGeer, P. L., and McGeer, E. G. (2008). Glial reactions in Parkinson's disease. Mov. Disord. 23, 474-483.

Miller, V. M., Lawrence, D. A., Mondal, T. K., and Seegal, R. F. (2009). Reduced glutathione is highly expressed in white matter and neurons in the unperturbed mouse brain-implications for oxidative stress associated with neurodegeneration. Brain Res. 1276, 22-30.

Moncada, S., and Bolanos, J. P. (2006). Nitric oxide, cell bioenergetics and neurodegeneration. J. Neurochem. 97, 1676-1689.

Moncada, S., and Erusalimsky, J.D. (2002). Does nitric oxide modulate mitochondrial energy generation and apoptosis? Nat. Rev. 3, 214-220.

Murphy, S., Simmons, M. L., Agulló, L., García, A., Feinstein, D. L., Galea, E., Reis, D. J., Minc-Golomb, D., and Schwartz, J. P. (1993). Synthesis of nitric oxide in CNS glial cells. Trends Neurosci. 16, 323-328.

Nair, A., Frederick, T. J., and Miller, S. D. (2008). Astrocytes in multiple sclerosis: a product of their environment. Cell. Mol. Life Sci. 65, 2702-2720.

Nehlig, A., and Coles, J.A. (2007). Cellular pathways of energy metabolism in the brain: is glucose used by neurons or astrocytes? Glia 55, 1238-1250.

Pacher, P., Beckman, J. S., and Liaudet, L. (2007). Nitric oxide and peroxynitrite in health and disease. Physiol. Rev. 87, 315-424.

Palacios-Callender, M., Hollis, V., Mitchison, M., Frakich, N., Unitt, D., and Moncada, S. (2007). Cytochrome c oxidase regulates endogenous nitric oxide availability in respiring cells: a possible explanation for hypoxic vasodilation. Proc. Natl. Acad. Sci. U.S.A. 104, 18508-18513.

Palacios-Callender, M., Quintero, M., Hollis, V. S., Springett, R. J., and Moncada, S. (2004). Endogenous NO regulates superoxide production at low oxygen concentrations by modifying the redox state of cytochrome $\mathrm{c}$ oxidase. Proc. Natl. Acad. Sci. U.S.A. 101, 7630-7635.

Palmer, R. M. J., Ferrige, A. G., and Moncada, S. (1987). Nitric oxide release accounts for the biological activity of endothelium-derived relaxing factor. Nature 327, 524-526.

Parihar, A., Vaccaro, P., and Ghafourifar, P. (2008). Nitric oxide irreversibly inhibits cytochrome oxidase at low oxygen concentrations: evidence for inverse oxygen concentration-dependent peroxynitrite formation. IUBMB Life 60, 64-67.

Park, L. C. H., Zhang, H., Sheu, K. F. R., Calingasan, N. Y., Kristal, B. S., Lindsay, J. G., and Gibson, G. E. (1999). Metabolic impairment induces oxidative stress, compromises inflammatory responses, and inactivates a key mitochondrial enzyme in microglia. J. Neurochem. 72, 1948-1958.

Parker, W. D. Jr., Filley, C. M., and Parks, J. K. (1990). Cytochrome oxidase deficiency in Alzheimer's disease. Neurology 40, 1302-1303.

Patel, R. P., and Darley-Usmar, V. M. (1996). Using peroxynitrite as oxidant with low-density lipoprotein. Meth. Enzymol. 269, 375-384.
Pearce, L. L., Pitt, B. R., and Peterson, J. (1999). The peroxynitrite reductase activity of cytochrome $c$ oxidase involves a two-electron redox reaction at the heme a(3)-Cu(B) site. J. Biol. Chem. 274, 35763-35767.

Pellerin, L., Bouzier-Sore, A. K., Aubert, A., Serres, S., Merle, M., Costalat, R., and Magistretti, P. J. (2007). Activitydependent regulation of energy metabolism by astrocytes: an update. Glia 55, 1251-1262.

Perea, G., Navarrete, M., and Araque, A. (2009). Tripartite synapses: astrocytes process and control synaptic information. Trends Neurosci. 32, 421-431.

Perry, T. L., Godin, D. V., and Hansen, S. (1982). Parkinson's disease: a disorder due to nigral glutathione deficiency? Neurosci. Lett. 33, 305-310.

Peuchen, S., Bolaños, J. P., Heales, S. J. R., Almeida, A., Duchen, M. R., and Clark, J.B. (1997). Interrelationships between astrocyte function, oxidative stress and antioxidant status within the central nervous system. Prog. Neurobiol. 52, 261-281.

Radi, R. (2004). Nitric oxide, oxidants, and protein tyrosine nitration. Proc. Natl. Acad. Sci. U.S.A. 101, 4003-4008.

Radi, R., Beckman, J. S., Bush, K. M., and Freeman, B. A. (1991). Peroxynitrite oxidation of sulfhydryls. The cytotoxic potential of superoxide and nitric oxide. J. Biol. Chem. 266, 4244-4250.

Radi, R., Cassina, A., Hodara, R., Quijano, C., and Castro, L. (2002). Peroxynitrite reactions and formation in mitochondria. Free Radic. Biol. Med. 33 , 1451-1464.

Radi, R., Rodríguez, M., Castro, L., and Telleri, R. (1994). Inhibition of mitochondrial electron transport by peroxynitrite. Arch. Biochem. Biophys. 308, 89-95.

Rodriguez, J.J., Olabarria, M., Chvatal,A. and Verkhratsky, A. (2009). Astroglia in dementia and Alzheimer's disease. Cell Death Differ. 16, 378-385.

Sandhu, J. K., Gardaneh, M., Iwasiow, R., Lanthier, P., Gangaraju, S., RibeccoLutkiewicz, M., Tremblay, R., Kiuchi, K., and Sikorska, M. (2009). Astrocytesecreted GDNF and glutathione antioxidant system protect neurons against 6OHDA cytotoxicity. Neurobiol. Dis. $33,405-414$.

Schweizer, M., and Richter, C. (1994) Nitric oxide potently and reversibly deenergizes mitochondria at low oxygen tension. Biochem. Biophys. Res. Commun. 204, 169-175.

Sharpe, M. A., and Cooper, C. E. (1998a). Interaction of peroxynitrite with mitochondrial cytochrome oxidase. J. Biol. Chem. 273, 30961-30972.

Sharpe, M. A., and Cooper, C. E. (1998b). Relations of nitric oxide with mitochondrial cytochrome c: a novel mechanism for the formation of nitroxyl anion and peroxynitrite. Biochem. J. 332, 9-19.

Stewart, V. C., Sharpe, M. A., Clark, J. B., and Heales, S. J. R. (2000). Astrocytederived nitric oxide causes both reversible and irreversible damage to the neuronal mitochondrial respiratory chain. J. Neurochem. 75 , 694-700.

Taylor, C. T., and Moncada, S. (2009). Nitric oxide, cytochrome $\mathrm{c}$ oxidase, and the cellular response to hypoxia. Arterioscler. Thromb. Vasc. Biol. doi: 10.1161/ATVBAHA.108.181628.

Tortora, V., Quijano, C., Freeman, B., Radi, R., and Castro, L. (2007). Mitochondrial aconitase reaction with nitric oxide, S-nitrosoglutathione, and peroxynitrite: mechanisms and relative contributions to aconitase inactivation. Free Radic. Biol. Med. 42, 1075-1088.

Uppu, R. M., Cueto, R., Squadrito, G. L., Salgo, M. G., and Pryor, W. A. (1996). Competitive reactions of peroxynitrite with 2'-deoxyguanosine and 7,8dihydro-8-oxo-2'-deoxyguanosine (8-oxodG): relevance to the formation of 8-oxodG in DNA exposed to peroxynitrite. Free Radic. Biol. Med. 21, 407-411.

Vargas, M. R., Johnson, D. A., Sirkis, D. W., Messing, A., and Johnson, J. A. (2008). Nrf2 activation in astrocytes protects against neurodegeneration in mouse models of familial amyotrophic lateral sclerosis. J. Neurosci. 28, 13574-13581.

Whitney, N. P., Eidem, T. M., Peng, H., Huang, Y., and Zheng, J. C. (2009). Inflammation mediates varying effects in neurogenesis: relevance to the pathogenesis of brain injury and neurodegenerative disorders. $J$. Neurochem. 108, 1343-1359.

Conflict of Interest Statement: The authors declare that the research was conducted in the absence of any commercial or financial relationships that could be construed as a potential conflict of interest.

Received: 09 December 2009; paper pending published: 23 December 2009; accepted: 18 January 2010; published online: 03 February 2010.

Citation: Bolaños JP and Heales SJR (2010) Persistent mitochondrial damage by nitric oxide and its derivatives: neuropathological implications. Front. Neuroenerg. 2:1. doi: 10.3389/neuro.14.001.2010 Copyright $\odot 2010$ Bolaños and Heales. This is an open-access article subject to an exclusive license agreement between the author and the Frontiers Research Foundation, which permits unrestricted use, distribution, and reproduction in any medium, provided the original authors and source are credited. 